\title{
Quantum crystallography of systems with agostic interactions
}

\section{A. Malaspina, S. Grabowsky}

University of Bern, Department of Chemistry, Biochemistry and Pharmaceutical Sciences, Freiestrasse 3, 3012 Bern, Switzerland,

\author{
lorraine.malaspina@dcb.unibe.ch
}

$\mathrm{C}-\mathrm{H}$ and Si-H bond activation by metal-hydrogen bonding (agostic interactions) plays a central role in catalytic processes [1]. These processes are directly dependent on metal-hydrogen bond energies. The versatility of the coordination modes of the heavy metals allows wide structure and topology variations of the complexes. Therefore, it is of major importance to accurately describe these chemical bonds.

One important drawback is the difficulty of deriving accurate and precise hydrogen atom positions by any kind of experiment. Neutron-diffraction experiments would be the only reliable source of such information, but there is a lack of available accurate X-H bond distances with $\mathrm{X}$ being a transition metal from neutron diffraction. Therefore, it would be desirable to determine both the elongation of the $\mathrm{C}-\mathrm{H}$ and $\mathrm{Si}-\mathrm{H}$ bonds in agostic interactions and the metal-hydrogen bonding parameters from standard X-ray diffraction experiments. In this context, the capabilities of Hirshfeld Atom Refinement [2] to obtain precise and accurate C-H/Si$\mathrm{H}$...X bond parameters (with $\mathrm{X}=$ transition metal) are tested.

Experimental and theoretical charge densities of agostic interactions involving transition metal compounds have been determined and analyzed in the past [3]. Here, we use a combination of HAR with subsequent X-ray constrained wavefunction fitting [4] and purely theoretical calculations on the accurate HAR and neutron geometries to analyze the related chemical bonding beyond a charge-density analysis. We use three different test systems: Figure la shows $\mathrm{Si}-\mathrm{H}$... Cu/Ag interactions enforced through the ligands used by proximity constraints. We discuss whether there are signatures of agostic interactions in these systems with closed-shell $\left(\mathrm{d}^{10}\right)$ coinage metal atoms. [5] Figure 1b shows a system where the proximity enforcing ligands have caused an oxidative addition reaction so that the hydrogen atom is now more closely bonded to the transition metal in a Rh-H...Si interaction. We analyze again to which extent (inverse) agostic interactions are present in this system. [6] Our findings will be referenced against classical $\mathrm{C}$-H...Ti agostic interactions found in titanium amides (Figure 1c).[7]

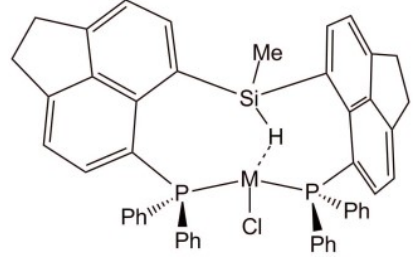

(a)

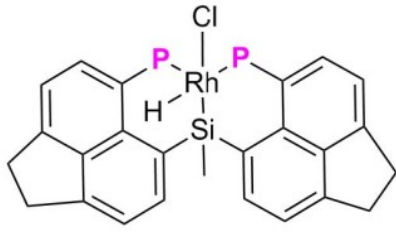

(b)

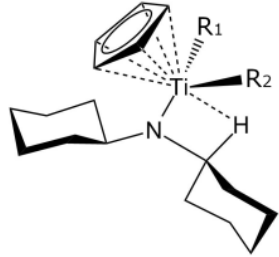

(c)

Figure 1. Compounds (a) $1 \cdot \mathrm{MCl}(\mathrm{M}=\mathrm{Cu}, \mathrm{Ag})$. Metal hydrides (b) $\mathrm{RhH}$, (c) Titanium amide compounds.

[1] Bäckvall, J. E. (2002). J. Organomet. Chem. 652(1-2), 105-111.

[2] Jayatilaka, D., Dittrich, B. (2008). Acta Cryst. A, 64, 383-393.

[3] (a) Scherer, W., Wolstenholme, D. J., Herz, V., Eickerling, G., Bruck, A., Benndorf, P., Roesky, P. W. (2010). Angew. Chem., Int. Ed., 49, 22422246. (b) Hauf, C.; Barquera-Lozada, J. E.; Meixner, P.; Eickerling, G.; Altmannshofer, S.; Stalke, D.; Zell, T.; Schmidt, D.; Radius, U.; Scherer, W. (2013). Z. Anorg. Allg. Chem., 639, 1996-2004.

[4] (a) Jayatilaka, D. (1998). Phys. Rev. Lett. 80, 798-801. (b) Jayatilaka, D., Grimwood, D. J. (2001). Acta Cryst. A, 57, 76-86.

[5] Hupf, E., Malaspina, L. A., Holsten, S., Kleemiss, F., Edwards, A. J., Price, J. R., Kozich, V., Heyne, K., Mebs, S., Grabowsky, S., Beckmann, J. (2019). Inorg. Chem., 58 (24), 16372-16378.

[6] Holsten, S., Malaspina, L.A., Mebs, S., Hupf, E., Grabowsky, S., Beckmann, J. (2021) Organometalics. Under revision.

[7] Adler, C., Bekurdts, A., Haase, D., Saak, W., Schmidtmann, M., \& Beckhaus, R. (2014). Eur. J. Inorg. Chem., 8, $1289-1302$.

Keywords: agostic interactions, quantum crystallography, hydrogen atom parameters, Hirshfeld Atom Refinement 